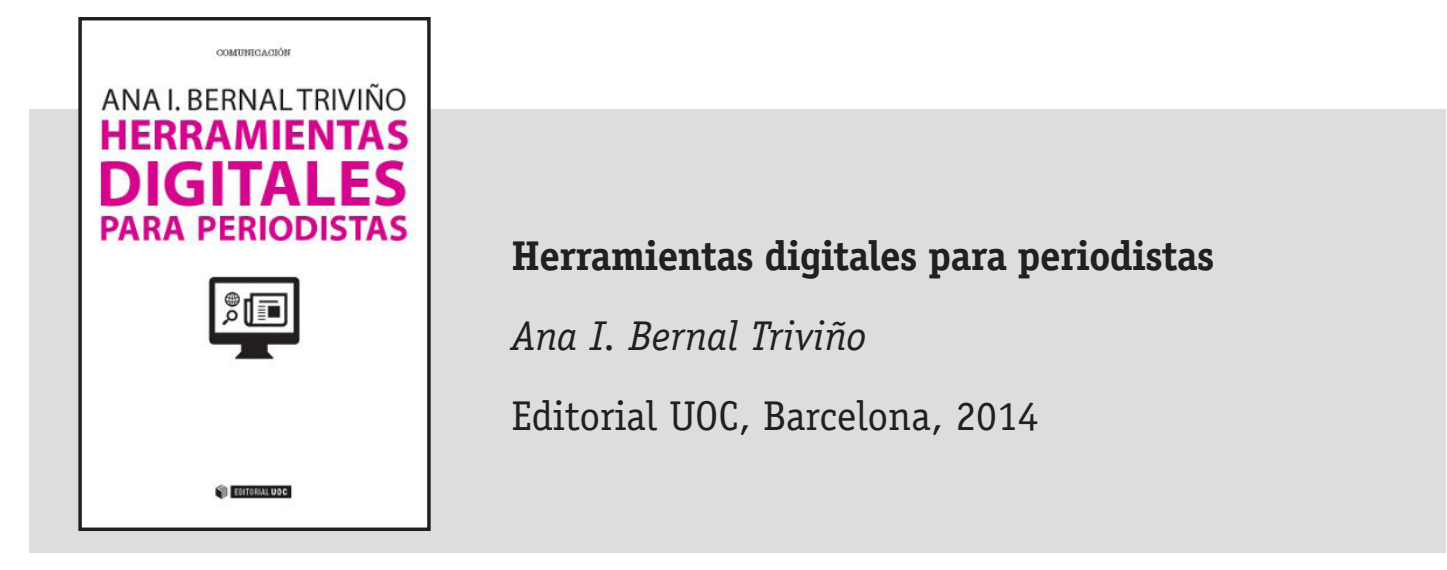

\title{
Autoayuda digital: de 'dummies' a expertos
}

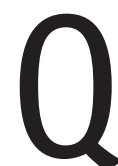

uien sienta que como periodista ha perdido el tren de los recursos digitales está de enhorabuena: Ana Bernal ha salido en su ayuda. El libro que ahora se comenta tiene una gran virtud, que es saberse una fuente didáctica y amplia, atrevida y consciente, sencilla y completa. Herramientas digitales para periodistas surge para desmontar mitos, tales como que a partir de una cierta edad ya no podemos aprender aspectos de las aplicaciones útiles para un comunicador, que muchos somos ajenos a la tecnología o que el ambiente de trabajo virtual es inseguro.

El libro de Bernal Triviño no escapa de la pasión que la autora siente por Picasso, y que emana en su visión de un periodismo "cubista y de los sentidos" (p.20). El volumen se organiza como una guía práctica. En la primera parte, breve, Bernal plantea los conceptos básicos sobre el periodismo digital, algunos de mucha enjundia. Por ejemplo, que algunos planes de estudio han olvidado que primero se es periodista y después digital (p.21) o que es más grave deshacerse de la ética periodística que perder la grabación de una entrevista exclusiva (p. 25). La segunda parte se dedica a las herramientas en sí, con una atractiva presentación por necesidades. "Necesito... encriptar un mensaje, o grabar una llamada de Skype". 
También familiarizar con la terminología de las herramientas digitales es uno de los objetivos de la obra. Esta parte práctica no deja de tener contenidos que llevan a reflexión, por ejemplo los que plantean los estándares de transparencia de las ciencias (p.65).

\section{Como usan los medios lo digital}

La autora no se olvida de dar ejemplos profesionales de como se usan estas aplicaciones, por ejemplo como utiliza Radio Nacional de España Wetransfer o Dropbox el Huffington Post (p.40). Personalmente, de las 175 herramientas que cita, llegué con conocimiento de causa hasta la 47, una nota muy baja, así que en mi caso el libro tiene un gran recorrido de aprendizaje. Aquellos aperos digitales pueden ser extremamente útiles en una profesión poblada de free-lance, a los que toca ser especialistas sin dejar de saber de todo un poco, como métodos seguros para enviar números de cuenta (p.52), crear contenidos multimedia (p.61) o editar fotografías o vídeos (p.67).

La búsqueda en el manual ofrece la organización por índice y por glosario, por lo que será sencillo hacer combinaciones para indagar a través de ejemplos o herramientas. La tercera parte del libro es otra parte imaginativa, un llamado "Botiquín de urgencia" que ayuda a localizar las herramientas, por si el índice y el glosario no fueran suficientes.

Es clara la vocación didáctica para que nadie se sienta ajeno a los entornos virtuales que nos son tan próximos y útiles. Hacer mapas, crear líneas de tiempo, crear un vídeo con el teléfono móvil para colgar en las redes sociales, no dependerá de que hayamos nacido después del final del franquismo. La profesión periodística no es el único campo al cual puede ser útil esta obra, ya que por ejemplo crear encuestas por Facebook o Twitter puede tener un uso académico evidente. Resulta, por lo tanto, un volumen sugerente, útil y pormenorizado, tanto para dummies como para avanzados digitales.

Dra. Carme Ferré-Pavia Departamento de Medios, Comunicación y Cultura Facultad de Ciencias de la Comunicación Universidad Autónoma de Barcelona 